\title{
Near Well CFD Simulation of SAGD Extra Heavy Oil Production
}

\author{
Amila C Kahawalage ${ }^{1}$ Vidar Mathiesen ${ }^{2}$ Britt Halvorsen ${ }^{1}$ \\ ${ }^{1}$ Department of Process, Energy and Environment, Telemark University College, Norway, \\ amilachandra@gmail.com, Britt.Halvorsenehit.no \\ ${ }^{2}$ InflowControl AS, Norway, vidar.mathiesendinflowcontrol.no
}

\begin{abstract}
Near well computational fluid dynamic simulation for extra heavy oil production using steam assisted gravity drainage was studied with ANSYS Fluent software. Computational fluid dynamic simulation can predict the multiphase flow behavior in the well annulus and the base pipe when the well involves an Autonomous Inflow Control Valve which is a promising approach for enhanced oil recovery. Volume of Fluid multiphase model was used to simulate the fluid behavior. Three different case studies were carried out by changing the volume fraction and the orientation of the valve. The mixing region of the two immiscible fluids is increased if the water volume fraction of the inlet from the reservoir to wellbore is increased. Simulation results showed that the valve orientation has an impact on oil/water separation.
\end{abstract}

Keywords: Extra heavy oil, computational fluid dynamics, Steam Assisted Gravity Drainage, Autonomous Inflow Control Valve, Volume of Fluid model

\section{Introduction}

Conventional oil deposits are depleting gradually as the oil consumption has been increasing due to rapid growth of global population, industry and technology. As a result, the demand for non-conventional oil is increased. Non-conventional oil can be categorized mainly as bitumen and heavy oil. Billions of oil barrels of heavy oils and bitumen have been deposited in the earth. However, it is not as easy to extract non-conventional oil as conventional oil. Bitumen and heavy oil can be extracted using several methods such as steam stimulation, steam assisted gravity drainage (SAGD), hot water flooding and in situ combustion (Butler, 1991).

\subsection{Background}

Generally in the SAGD process which is the focal point of interest in this study, two horizontal wells are drilled as shown in Figure 1. When high pressure steam is injected to one wellbore (upper), oil is heated and drained into the second (lower) wellbore due to reduction of viscosity and then pumped out.

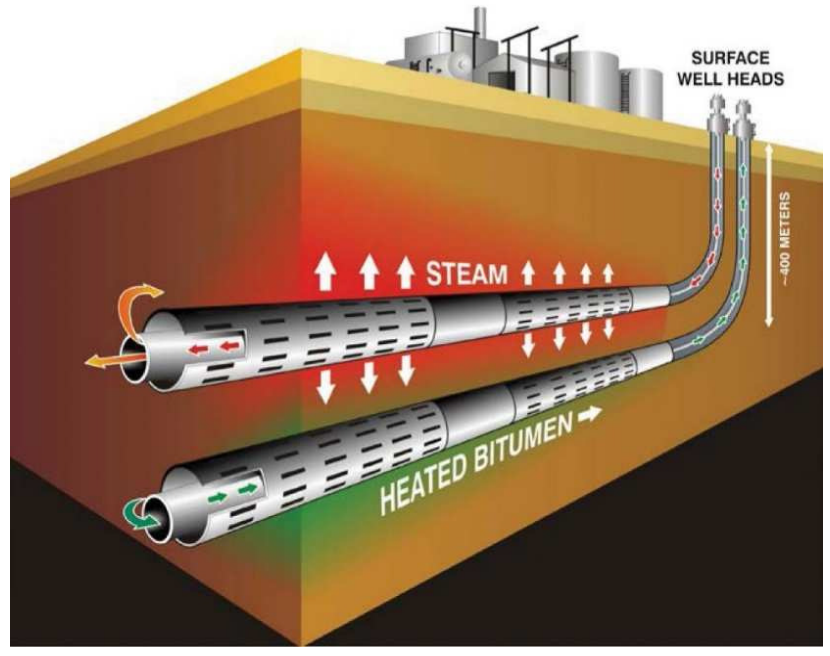

Figure 1: SAGD operation

(Drilling Engineering Association, 2012)

Bitumen and heavy oil are highly viscous at reservoir conditions. By steam injection, bitumen and heavy oil are converted to low viscous fluids, which are mobile through the pipes from reservoir to ground. Injected steam is condensed and drained with oil to the production well. Hence, not only oil but also water is pumped out. If production well produces an oil water mixture, then there will be an additional cost for oil/water separation at the production site, and also the possibilities are high for ground water pollution with oily water coming out from the production well. To overcome this problem, Inflow Control Device (ICD) was introduced by Norsk Hydro in Troll field in 1990s. (Al-Khelaiwi, 2013)

After introduction of ICD by Norsk Hydro, the technology has been continuously developing and the Autonomous Inflow Control Device (AICD) is a typical example of this development. AICD does not require control from the surface as it is basically operated based on change in the fluid characteristics. AICD in oil and gas fields has the ability to choke the influx of gas or water to the production pipe. However, Inflow Control Valves (ICVs) provide solutions to this. ICVs can be 
controlled remotely or autonomously. Autonomous inflow control valves (AICVs) (Aakre et al., 2013) are capable to differentiate between fluids based on the physical properties of the fluids, such as density and viscosity.

\subsection{Objective}

The AICV functionality highly depends on the flow behavior around the valve and near well. Theoretically, if any well segment with AICV receives water, the valve should close autonomously, and the production from this segment will stop. Volume fraction of each phase as well as physical properties of the fluids affect the flow behavior. In this study, this scenario is analyzed by varying the process conditions because the operation of AICV can be improved and shortcomings can be reduced by analyzing the flow behavior.

\section{Basic Principle and Geometry of AICV}

Following description includes the operational mechanism of AICV which is manufactured by InflowControl AS, Norway. The AICV functionality is established on the difference in the pressure drop in a laminar flow restrictor compared to turbulent flow restrictor. Pressure drop through the laminar flow restrictor can be estimated using equation (1).

$$
\Delta p=\frac{32 \mu \nu L}{D^{2}}
$$

Pressure drop through the pipe segment is given in equation (2)

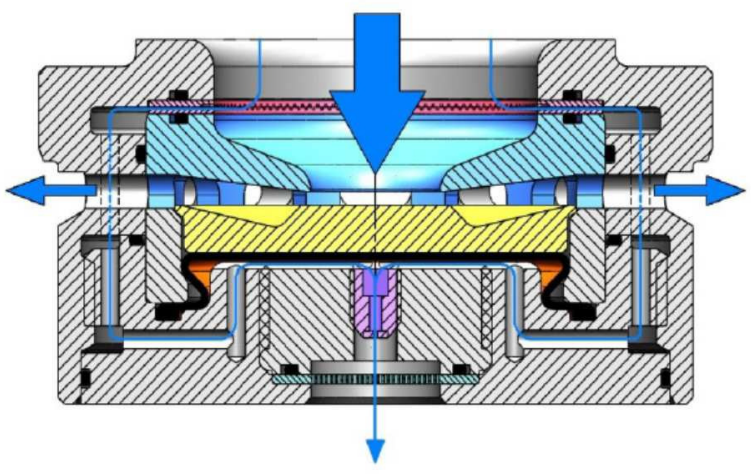

(a)

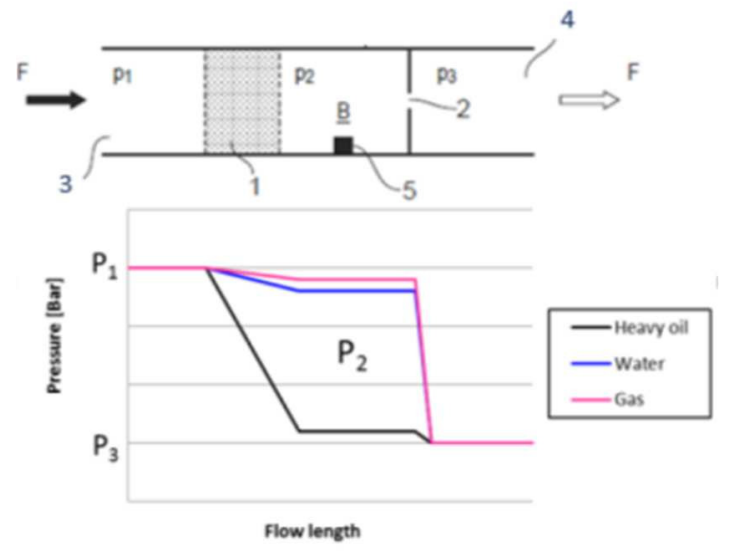

Figure 2. Combination of laminar and turbulent flow restrictors in series (Aakre et al., 2014)

is a geometrical constant. Figure 2 represents the laminar and turbulent flow restrictors in series. According to Figure 2, position 1 and 2 represents the laminar and turbulent flow restrictors respectively; position 3 represents the inlet to the valve from the annulus and position 4 indicates the outlet from the valve to the base pipe. Fluid properties and flow rates influence the pressure in chamber $B$. This pressure is the key element which is used to control the valve. When the pressure drop through the laminar flow element is high as in heavy oil, the valve is open. When low viscous fluids such as gas or water flows through the laminar flow element the pressure drop is low but the pressure in chamber B is high enabling the valve to be closed. Figure 3 illustrates the open and closed positions

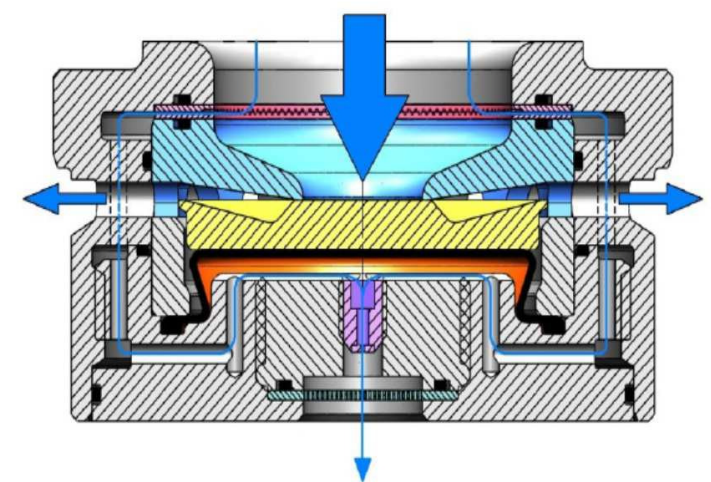

(b)

Figure 3. Open and close position of AICV: (a) open; (b) close (Aakre et al., 2014)

$$
\Delta p=k \frac{1}{2} \rho v^{2}
$$

where $\mu$ is the fluid viscosity, v is the fluid velocity, $\rho$ is the fluid density and L and D are the length and diameter of the laminar flow element respectively and $k$ of the AICV_(Aakre et al., 2014). According to Figure $3(\mathrm{a})$, the thickest blue arrow shows the inlet of the main flow to the valve, and the two horizontal arrows show the outlet of the main flow to the base pipe. Location which are marked by dashed line in Figure 4, are referred as nozzles hereafter in this paper. 

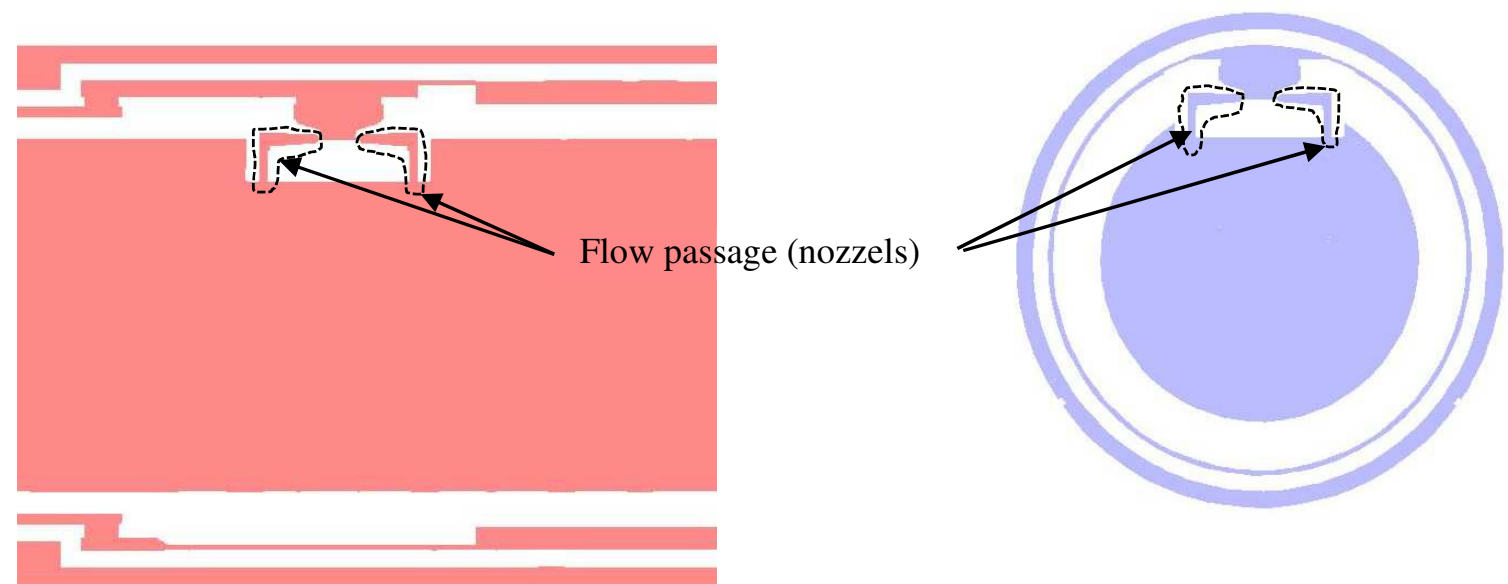

Figure 4 .Representation of nozzles for two different sections

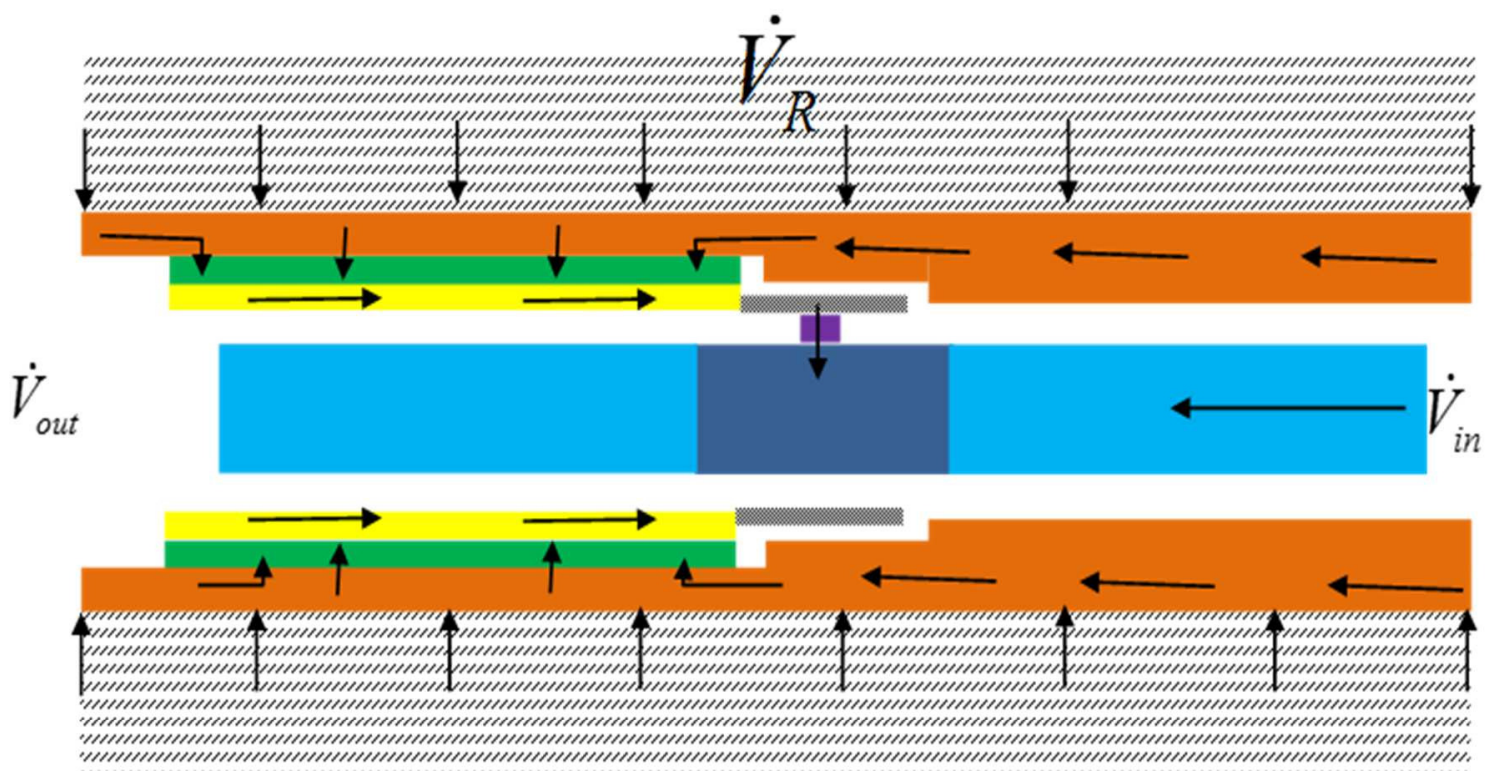

Wellbore (Annulus)

Sand screen

Annulus between Sand screens

and AICV section

"IIIIIII)

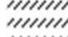

\section{Reservoir}

\section{AICV section Annulus}

AICV

AICV pipe

Fluid zone

Indicates the flow direction of oil and water mixture

Figure 5. Overview of the simulation model 


\section{Methodology and ANSYS Fluent Setup}

\subsection{Simulation Procedure}

The complete model used for this study, is described in this section. Oil and water mixture which comes from the reservoir is collected in the wellbore and enters into the annulus through the sand screen. Finally the mixture goes to the production pipe through the AICV and gets mixed with oil which comes from other segments of the well (Figure 5). The near well temperature was considered as constant as $213{ }^{\circ} \mathrm{C}$. Three boundary conditions are defined in the model and they are described in Table 1.

Table 1. Description of inlets and outlets

\begin{tabular}{|l|l|}
\hline Inlet/Outlet & Description \\
\hline Inlet I & $\begin{array}{l}\text { Total flow rate comes from the } \\
\text { reservoir into the wellbore. } \\
\text { Volume flow rate }\left(\dot{V}_{R}\right) \text { is fixed for } \\
\text { all simulations and its value is 1 } \\
\text { m3/h. } \dot{V}_{R} \text { is divided into two inlets } \\
\text { according to the volume fraction } \\
\text { of each fluid. }\end{array}$ \\
\hline Inlet II & $\begin{array}{l}\text { Extra Heavy oil and water flow } \\
\text { rate that comes from other well } \\
\text { segments ( } \dot{V}_{\text {in }} \text { ) are also kept } \\
\text { constant and the value is } 3 \text { m3/h. } \\
\text { It is assumed that there are no } \\
\text { water in the inlet ( } \dot{V}_{\text {in }} \text { ). }\end{array}$ \\
\hline Outlet I & $\begin{array}{l}\text { Its condition is kept as a pressure } \\
\text { outlet and its value is 28 bar } \\
\text { (gauge). }\end{array}$ \\
\hline
\end{tabular}

However, only the AICV geometry are considered in the simulations but not the AICV function. To observe how the simulation is affected by the volume fraction of each fluid in Inlet I, the volume fractions were changed while keeping the total volume flow rate constant.

Simulations were performed when the AICVs were mounted with different orientations in the base-pipe so that the valve position was also changed, to investigate the flow behavior according to the valve orientation. This is shown in Table 2.

Table 2. Different valve positions

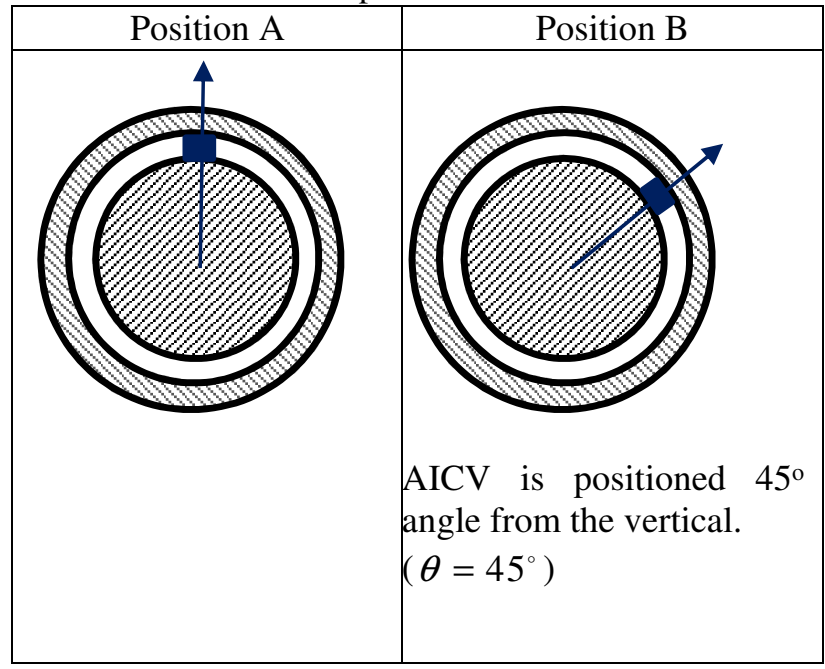

The flow behavior was investigated and the description of all the case studies is shown in Table 3.

\subsection{Geometry Modeling and Meshing}

The total geometry model consists of six main parts as shown in Figure 5. The main parts are the AICV section, the inlet pipe, the outlet pipe, the annulus between the

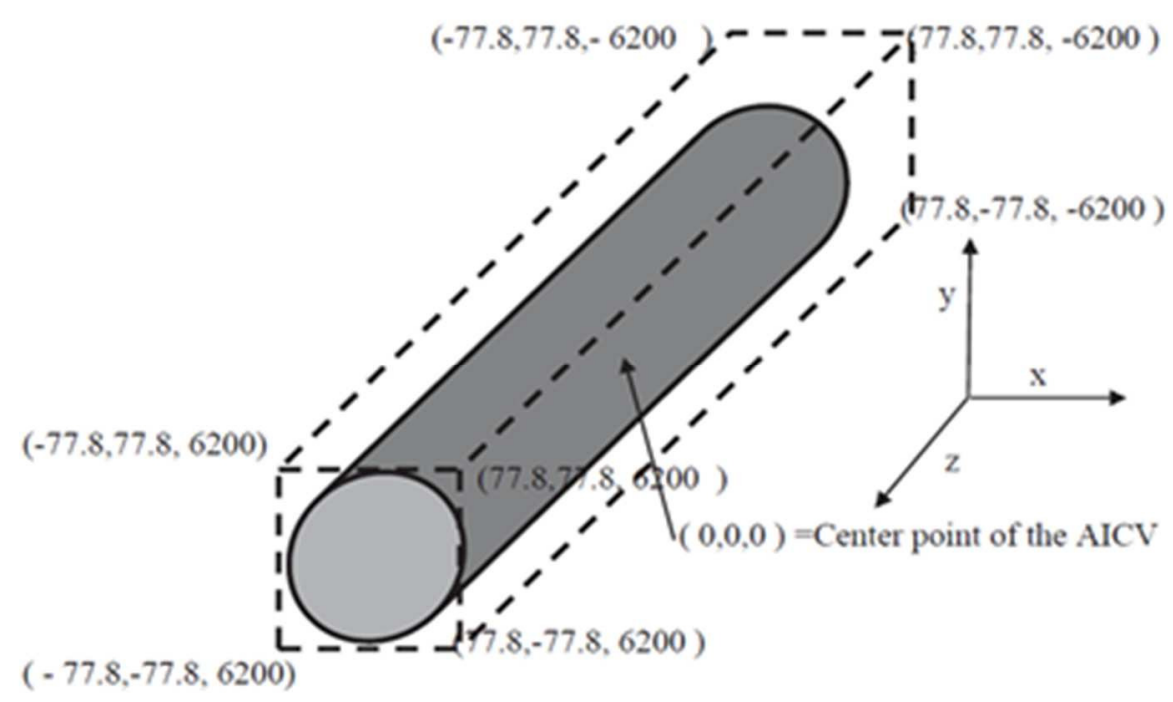

Figure 6. Coordination of the model boundaries (dimensions are in $\mathrm{mm}$ )

The objective of the simulations is to investigate the flow behavior of heavy oil and water in the entire model. sand screen and the AICV section, the sand screen and the wellbore. Each part was modelled separately as 
multibody parts and finally assembled into one geometry. Coordination of the model boundaries is shown in Figure 6.

Meshing was created using ANSYS Meshing Tool. The min size, max face size, max size and growth rate were set to $0.001 \mathrm{~m}, 0.0065 \mathrm{~m}, 0.01 \mathrm{~m}$ and 1.2 respectively in the global setting for all simulations. Each part was meshed separately. The element number and number of nodes for CASE 1 and CASE 2 were 1304220 and 1179132 respectively. The element number and number of nodes for CASE 3 were 1300200 and 1304778. Cross section of the generated mesh is shown in Figure 7.

Table 3. Different case studies for simulations

\begin{tabular}{|l|c|c|c|}
\hline Parameter & $\begin{array}{c}\text { CASE } \\
1\end{array}$ & $\begin{array}{c}\text { CASE } \\
2\end{array}$ & $\begin{array}{c}\text { CASE } \\
3\end{array}$ \\
\hline $\begin{array}{l}\text { Oil volume fraction in } \\
\text { Inlet I }\end{array}$ & 0.7 & 0.5 & 0.7 \\
\hline $\begin{array}{l}\text { Water volume fraction } \\
\text { in Inlet I }\end{array}$ & 0.3 & 0.5 & 0.3 \\
\hline AICV position & $\mathrm{A}$ & $\mathrm{A}$ & $\mathrm{B}$ \\
\hline
\end{tabular}

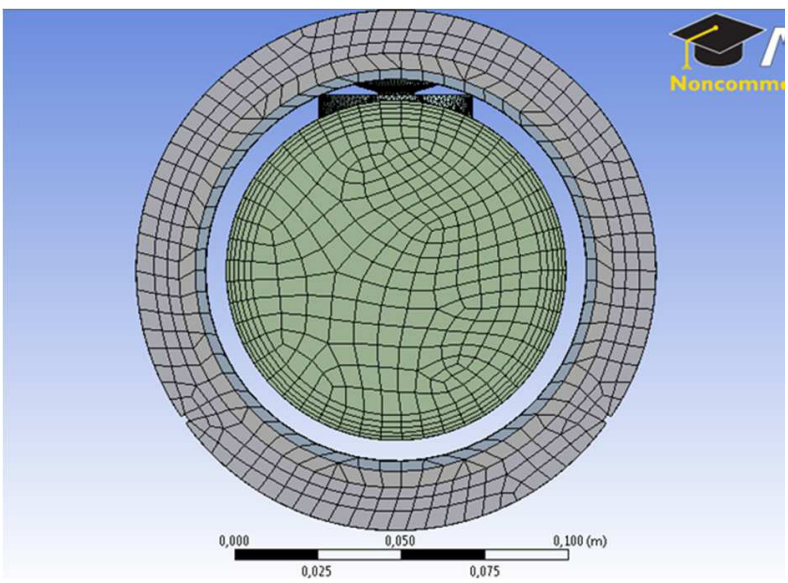

Figure 7. Cross section of generated mesh

\subsection{ANSYS/Fluent Setup}

All the simulations were performed with pressure based solver because both heavy oil and water can be considered as incompressible liquids. Simulations were carried out with transient mode to achieve proper steady state. The volume of fluid (VOF) multiphase model was selected as stratified oil and water multiphase flow was considered in horizontal pipes (Mohammed et al., 2011). Heavy oil density and viscosity were defined according to the temperature and pressure $(213 \mathrm{oC}$ and 28 barg) as given in Table 4.

The sand screen was modeled as a porous media in the CFD simulation. For the modeling purposes slotted sand screen was selected which has $3 \%$ open area (PetroWiki, 2015, Xie et al., 2007), with the dimension of $3.81 \mathrm{~cm}$, $0.03556 \mathrm{~cm}$ and $1 \mathrm{~cm}$ as length, width and depth respectively. Power law was used to define the porous media.
Table 4. Fluid properties for case studies $\left(213{ }^{\circ} \mathrm{C}\right.$ and 28 barg)

\begin{tabular}{|l|c|c|}
\hline Fluid & Density $\left[\mathrm{kg} / \mathrm{m}^{3}\right]$ & Viscosity [cp] \\
\hline Water & 848 & 0.1255 \\
\hline Extra heavy oil & 826 & 8.35 \\
\hline
\end{tabular}

The three main boundary conditions in the simulation are described in Table 1. Inlet I has two sub inlets for water and heavy oil. For the water and oil inlet, the boundary type was selected as mass flow and the flow direction was set to be normal to the boundary.

SIMPLE (Semi-Implicit Method for Pressure-Linked Equations) was selected as the Pressure Velocity Coupling method for the simulations in CASE 1 and CASE 2. SIMPLEC (Semi-Implicit Method for Pressure-Linked Equations Consistent) was selected for CASE 3. PRESTO! (PREssure STaggering Option), Power law and Modified HRIC (High Resolution Interface Capturing) was selected as the Spatial Discretization methods for pressures, momentum and volume fraction respectively.

Table 5. Maximum normalized equation residuals

\begin{tabular}{|l|c|}
\hline Property & Normalized equation residuals \\
\hline Continuity & $10^{-5}$ \\
\hline $\mathrm{X}, \mathrm{Y}$ and $\mathrm{Z}$ velocity & $10^{-5}$ \\
\hline $\mathrm{K}$ & $10^{-4}$ \\
\hline Epsilon & $10^{-4}$ \\
\hline Vf-phase-2 & $10^{-4}$ \\
\hline
\end{tabular}

Convergence was decided based on two criteria. The normalized equation residuals for the momentum, continuity, turbulence and volume fraction equations were monitored and would desirably drop as shown in Table 5. However, this criterion alone is not enough for deciding the validity of the solution. For some cases the residual criterion might never be fulfilled even though the solution is valid and for other cases the solution can be incorrect even though the residuals are low. Therefore, volume fraction of oil and mixture velocity at position $(0,0,0)$ was also monitored. When these monitored values remained constant for more than 100 time steps, the simulation was considered at steady state and converged.

Table 6. Description of planes and lines

\begin{tabular}{|l|l|}
\hline Plane No & Description \\
\hline Plane 01 & $\mathrm{Z}=0$ plane; goes through the AICV \\
\hline Plane 02 & $\begin{array}{l}\mathrm{Z}=1000 \mathrm{~mm} \text { plane, goes through the } \\
\text { base pipe, sand screen and well } \\
\text { annulus }\end{array}$ \\
\hline Plane 03 & $\begin{array}{l}\mathrm{X}=0 \text { plane; goes through the AICV as } \\
\text { well as base pipe centerline }\end{array}$ \\
\hline
\end{tabular}




\section{Results and Discussion}

The simulation results are discussed in this section. For better explanation, data were extracted from several planes for each case, and the location of each plane in the 3D structure are shown in Figure 8 and Table 6.

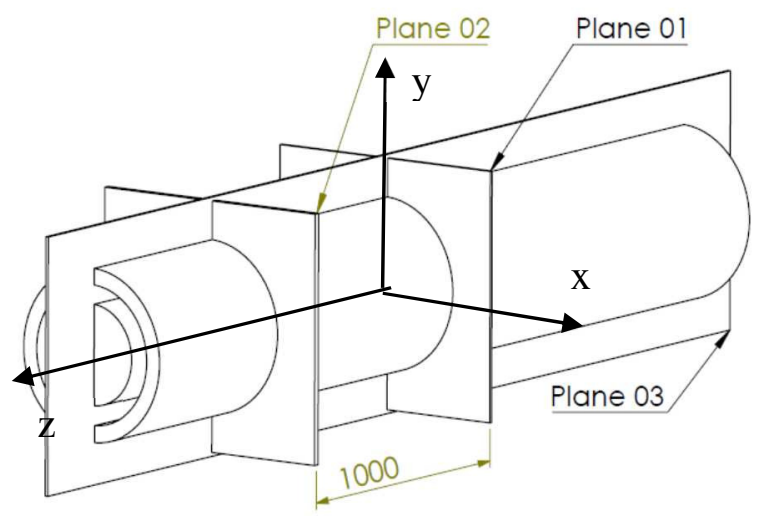

Figure 8. Overview of planes

Figure 9(a) and (b), show the oil phase which remains on the top and the water phase which stays at bottom in the wellbore. In CASE 1 and CASE 2, the inlet oil
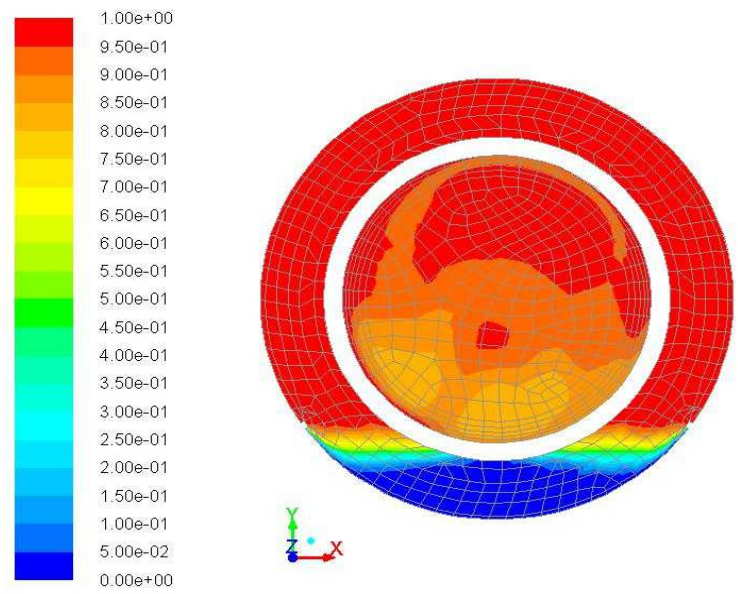

(a) wellbore and also in the AICV annulus section is observed. Higher water level are obtained in the AICV annulus section in CASE 2 compared to CASE 1. This is because the water volume fraction in Inlet I is $50 \%$ in CASE 2 and $30 \%$ in CASE 1. When considering the AICV region, CASE 2 has more water than CASE 1. It can be seen in CASE 2 that the oil and water mixture through the AICV, is mixing with the oil flow in the pipe. The mixing region is larger in CASE 2 because of the higher volume flow rate of water to the well.

Figure 11(a) and (b) show the oil volume fraction of the cross sectional plane which goes through plane 03 for CASE 1 and CASE 2 respectively. Through this plane two nozzles are indicated. Considering CASE 1 only one nozzle injects oil/water mixture whereas in CASE 2 both nozzles inject mixed flow. Also in CASE 2 there is a larger mixing region than in CASE 1. The longer mixing region is due to higher volume flow rate of the water in CASE 2 than in CASE 1.

Figure 10(a) and Figure 12(a) show the oil volume fraction of the cross sectional plane going through the plane 01 for CASE 1 and CASE 3 respectively. It can be observed that water gets separated in the right side in the AICV annulus in CASE 3 but in CASE 1 water gets separated in the bottom. This indicates that water is
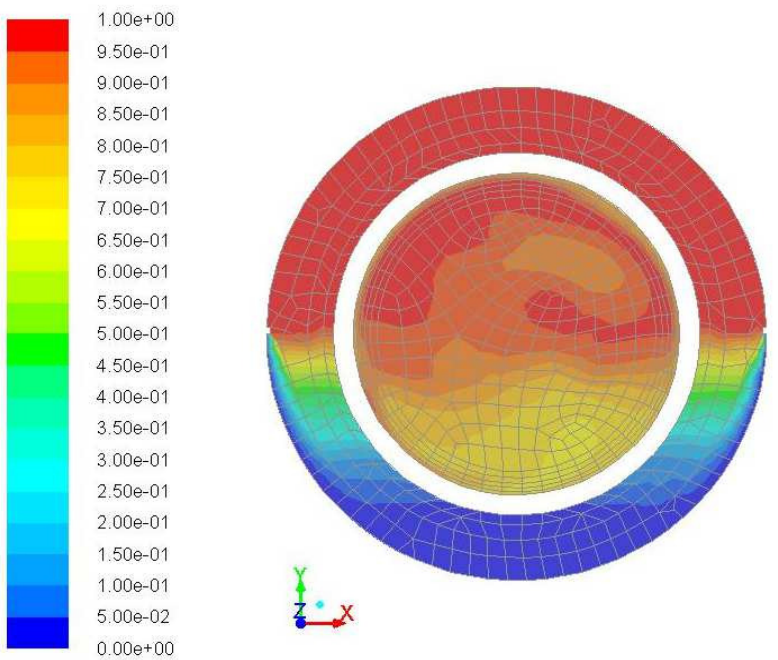

(b)

Figure 9. Extra heavy oil volume fraction through plane 02 for; (a) CASE 1 and (b) CASE 2

volume fraction from reservoir is 0.7 and 0.5 respectively. The interface layer between oil and water is thicker in CASE 2 than in CASE 1. Water separation in the production pipe is observed in both cases and the water level is higher in CASE 2.

Figure 10 (a) and (b) show oil volume fraction in the cross sectional plane going through the centerline of the AICV for CASE 1 and CASE 2 respectively. As described above, oil and water separation in the injected to the production pipe through the lower nozzle in CASE 3, which implies that water has chosen the easiest way to enter the production pipe. In the other cases, the nozzles are located on the top of the pipe whereas in CASE 3 the nozzles are located close to the bottom of the pipe, hence water entering from these nozzles gets separated more quickly than in the other cases (refer Figure 11(a) and Figure 12(b)). 


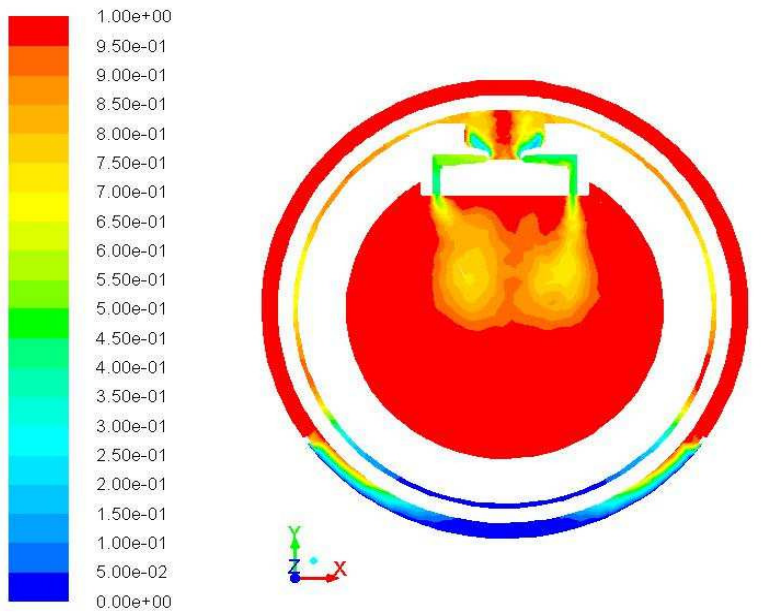

(a)

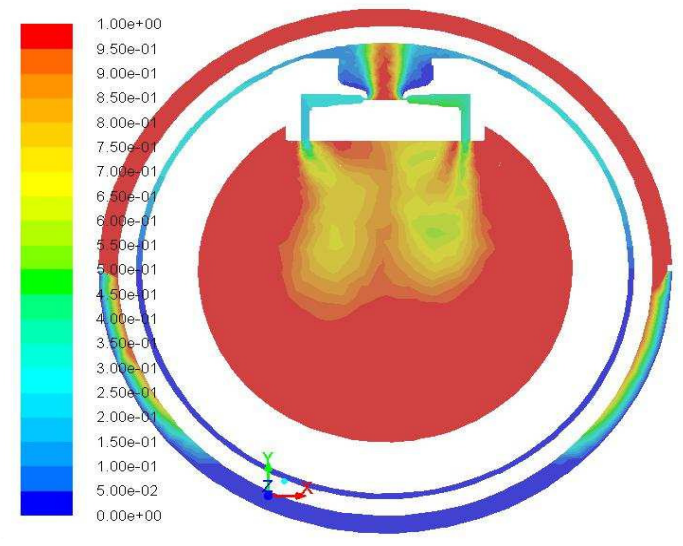

(b)

Figure 10. Extra heavy oil volume fraction through plane 01 for; (a) CASE 1 and (b) CASE 2

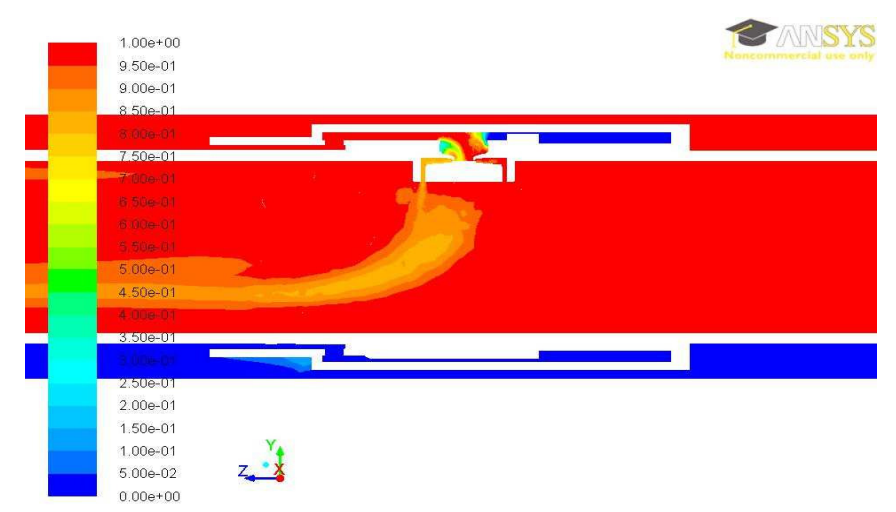

(a)

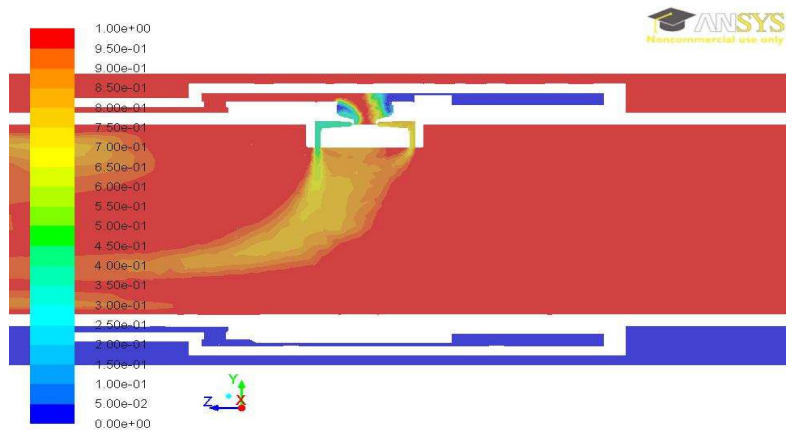

(b)

Figure 11. Extra Heavy Oil volume fraction through the Plane 03 for; (a) CASE 1 (b) CASE 2
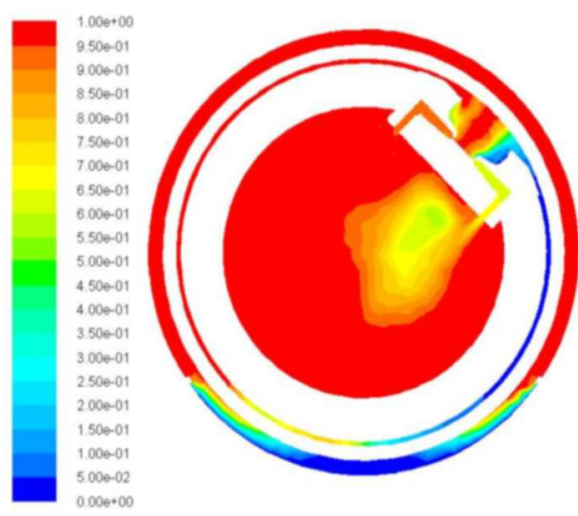

(a)

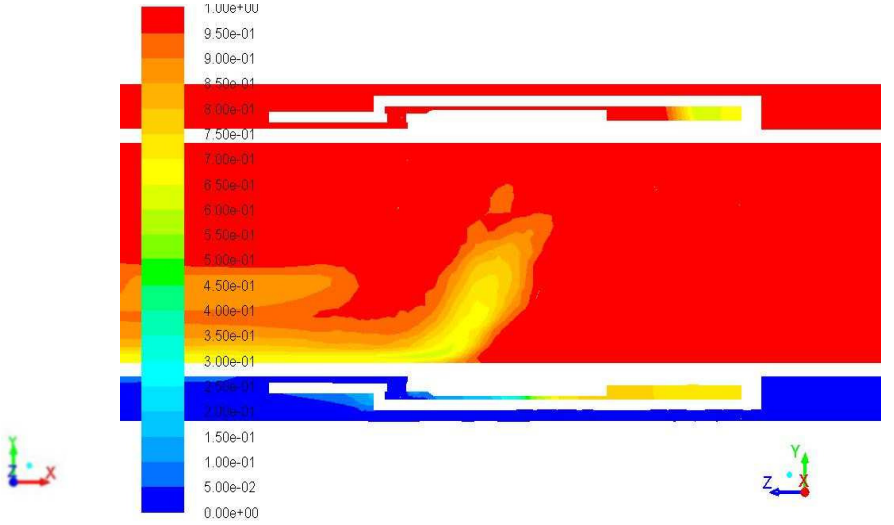

(b)

Figure 12. Extra Heavy Oil volume fraction for CASE 3 through the plane (a) 01 (b) 03 


\section{Conclusion}

In this study, CFD simulations were carried out using ANSYS Fluent to investigate the flow behavior in production of extra heavy oil with AICV in combination with the SAGD process in the near well area.

The simulations results show that VOF model can be used for prediction of flow behavior in near well reservoir. The denser fluid which is water gets separated at the bottom of the wellbore and the oil accumulates on the top. When the water volume fraction at the inlet from reservoir to the wellbore is increased, the mixing region is increased. When the valve orientation is changed it affects to the oil/water separation process.

\section{References}

AAKRE, H., HALVORSEN, B., WERSWICK, B. \& MATHIESEN, V. 2013. Smart Well With Autonomous Inflow Control Valve Technology. SPE Middle East Oil and Gas Show and Conference. Baharain: Society of Petroleum Engineers.

AAKRE, H., HALVORSEN, B., WERSWICK, B. \& MATHIESEN, V. 2014. Autonomous Inflow Control Valve for Heavy and Extra-Heavy Oil. SPE Heavy and Extra Heavy Oil Conference. Colombia: Society of Petroleum Engineers.

AL-KHELAIWI, F. T. M. 2013. A Comprehensive Approach to the Design of Advanced Well Completions. Doctor of Philosophy, HeriotWatt University.

BUTLER, R. M. 1991. Thermal Recovery of oil and Bitumen, New Jersey, Prentice-Hall. Inc.

MOHAMMED, A., AL-YAARI, BASEL, F. \& ABUSHARKH 2011. CFD Prediction of Stratified Oil-Water Flow in a Horizontal Pipe. Asian Transactions on Engineering, 5, 68-75.

PETROWIKI. 2015. Slotted liners and wire wrapped screens [Online]. Texas: Society of Petroleum Engineers. Available:

http://petrowiki.org/Slotted_liners_and_ wire_wrapped_screens [Accessed 01 April 2015].

XIE, J., JONES, S. W., MATTHEWS, C. M., WAGG, B. T., PARKER, P. \& DUCHARME, R. 2007. Slotted liner design for SAGD wells. In: OIL, W. (ed.) World Oil. Houston. 